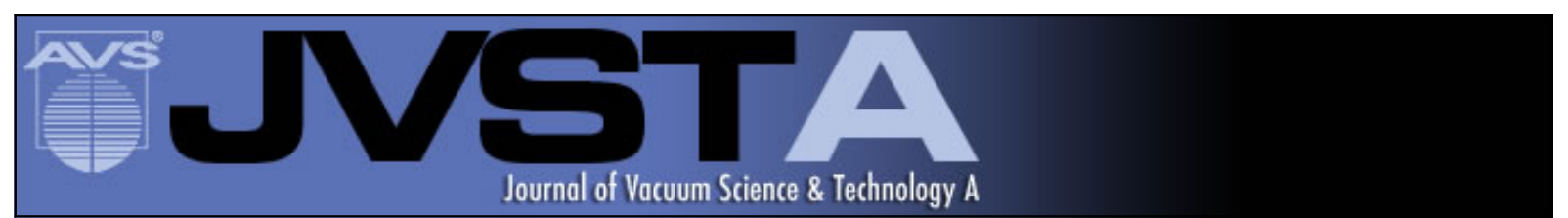

\title{
Dynamic XPS measurements of ultrathin polyelectrolyte films containing antibacterial Ag-Cu nanoparticles
}

Merve Taner-Camc and Sefik Suzer

Citation: Journal of Vacuum Science \& Technology A 32, 021510 (2014); doi: 10.1116/1.4862155

View online: http://dx.doi.org/10.1116/1.4862155

View Table of Contents: http://scitation.aip.org/content/avs/journal/jvsta/32/2?ver=pdfcov

Published by the AVS: Science \& Technology of Materials, Interfaces, and Processing

\section{Articles you may be interested in}

Size and alloying induced shift in core and valence bands of $\mathrm{Pd}-\mathrm{Ag}$ and $\mathrm{Pd}-\mathrm{Cu}$ nanoparticles

J. Appl. Phys. 115, 124301 (2014); 10.1063/1.4869437

Enhanced hydrogenation and reduced lattice distortion in size selected $\mathrm{Pd}-\mathrm{Ag}$ and $\mathrm{Pd}-\mathrm{Cu}$ alloy nanoparticles Appl. Phys. Lett. 103, 173107 (2013); 10.1063/1.4826580

Ag-Cu catalysts for ethylene epoxidation: Selectivity and activity descriptors

J. Chem. Phys. 138, 184707 (2013); 10.1063/1.4803157

Effects of FeCo magnetic nanoparticles on microstructure of Sn-Ag-Cu alloys

J. Appl. Phys. 113, 17 A301 (2013); 10.1063/1.4793502

$\mathrm{Ag} / \mathrm{Cu}(100)$ Surface Alloy and Polycrystalline $\mathrm{Cu}(\mathrm{Ag})$ Alloy Studied by XPS

Surf. Sci. Spectra 15, 31 (2008); 10.1116/11.20060701

\section{Instruments for advanced science}
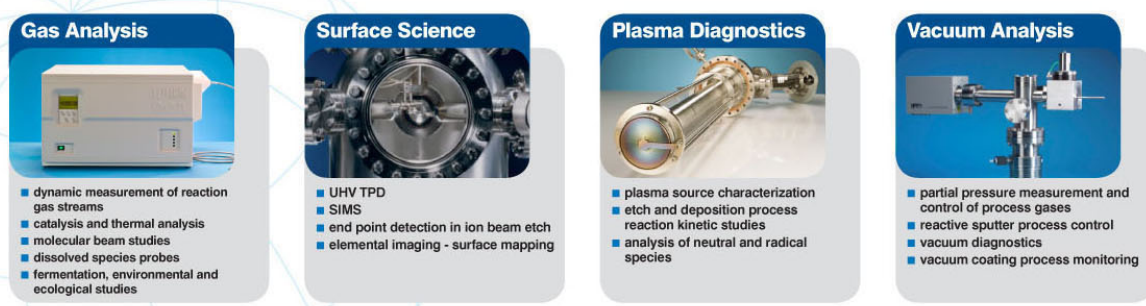

contact Hiden Analytical for further details

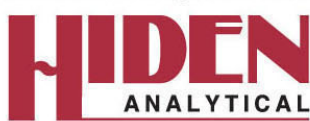

info@hideninc.com www.HidenAnalytical.com CLICK to view our product catalogue 


\title{
Dynamic XPS measurements of ultrathin polyelectrolyte films containing antibacterial Ag-Cu nanoparticles
}

\author{
Merve Taner-Camcı and Sefik Suzer ${ }^{\text {a) }}$ \\ Department of Chemistry, Bilkent University, 06800 Ankara, Turkey
}

(Received 19 October 2013; accepted 2 January 2014; published 22 January 2014)

\begin{abstract}
Ultrathin films consisting of polyelectrolyte layers prepared by layer-by-layer deposition technique and containing also $\mathrm{Ag}$ and $\mathrm{Cu}$ nanoparticles exhibit superior antibacterial activity toward Escherichia coli. These films have been investigated with XPS measurements under square wave excitation at two different frequencies, in order to further our understanding about the chemical/physical nature of the nanoparticles. Dubbed as dynamical XPS, such measurements bring out similarities and differences among the surface structures by correlating the binding energy shifts of the corresponding XPS peaks. Accordingly, it is observed that the Cu2p, Ag3d of the metal nanoparticles, and S2p of cysteine, the stabilizer and the capping agent, exhibit similar shifts. On the other hand, the $\mathrm{C} 1 \mathrm{~s}, \mathrm{~N} 1 \mathrm{~s}$, and $\mathrm{S} 2 \mathrm{p}$ peaks of the polyelectrolyte layers shift differently. This finding leads us the claim that the $\mathrm{Ag}$ and $\mathrm{Cu}$ atoms are in a nanoalloy structure, capped with cystein, as opposed to phase separated entities. (C) 2014 American Vacuum Society. [http://dx.doi.org/10.1116/1.4862155]
\end{abstract}

\section{INTRODUCTION}

Nanosized metallic particles have been in the focus of scientists as a consequence surface modification in a large variety of fields including electronics, biology, catalysis, optics, chemical, and biosensing. ${ }^{1-8}$ In our previous work, we had shown that suitably synthesized and stabilized $\mathrm{Ag}$ and $\mathrm{Cu}$ bimetallic nanoparticles yielded an enhanced antibacterial property compared to their monometallic counterparts. ${ }^{9}$ However, there are major problems with the stability of the $\mathrm{AgCu}$ nanoparticles since (i) they are known to phase separate in the bulk ${ }^{10}$ and (ii) they have relative ease of oxidation of $\mathrm{Cu}$ in ambient. Both of these have adverse effects on the long-term effectiveness of their antibacterial properties. In addition, structural information about these bimetallic nanoparticles has been very elusive since we were not able to obtain any x-ray diffraction (XRD) pattern, no matter how much we had tried, which was also reported by Yun et al. ${ }^{11}$

Layer-by-layer (LbL) deposition technique has been quite successful for construction of stable ultrathin multilayer films containing metal nanoparticles, due to strong electrostatic forces between charged polyelectrolytes and oppositely charged colloidal nanoparticles. ${ }^{12-19}$ This is the technique we have adopted to construct our ultrathin layers with strong antibacterial properties.

Common characterization tools of metal nanoparticles within ultrathin films, among others, include NMR, IR, Raman, and UV-visible spectroscopy, electron and scanning tunneling microscopy, and XRD techniques. ${ }^{20-29}$ X-ray photoelectron spectroscopy (XPS) has also been one of the major analysis techniques of nanoparticles with high precision and sensitivity, since it provides information derived from the outermost atomic layers with about $1-15 \mathrm{~nm}$ probe length, which matches perfectly our ultrathin films..$^{30,31} \mathrm{In}$ conventional, static XPS measurements, the sample is

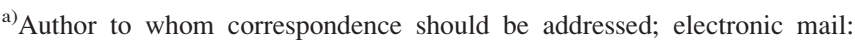
suzer@fen.bilkent.edu.tr
}

grounded and a flood gun, which provides low energy electrons and/or ions, is used to compensate the charge left by the outgoing photoelectrons. Chemically specific and quantitative information are derived from measured binding energy and intensity of the peaks.

For dynamic XPS measurements, mainly developed by our group, the sample is not grounded but connected to a time varying external voltage stimuli, effecting the charging of the surface structures. Among the forms of voltage stimuli, square wave (SQW) modulation with different frequency is the most simple to interpret the results of. The SQW modulation leads to twinning of all XPS peaks, and the difference between the twinned peak positions gives information about dynamics of charging/discharging of the surface moieties related, which in turn can be used for extracting additional analytical information. ${ }^{32-35}$

\section{EXPERIMENT}

Poly (allylaminehydrochloride) (PAH), polyethyleneimine (PEI), poly (sodium 4-styrene sulfonate) (PSS), and sodium citrate dihydrateand copper (II) acetate monohydrate were purchased from Sigma-Aldrich. Sodium chloride $(\mathrm{NaCl})$, sodium hydroxide $(\mathrm{NaOH})$, and hydrazine hydrate $(\mathrm{HH})$ were obtained from Merck. Silver nitrate $\left(\mathrm{AgNO}_{3}\right)$ and L-cysteine $\left(\mathrm{C}_{3} \mathrm{H}_{7} \mathrm{NO}_{2} \mathrm{~S}\right)$ were acquired from Fluka. The water used in all experiments was prepared in a three-stage Millipore Milli-Q Synergy 185 purification system. Glasses that are used for thin film construction were obtained from ISOLAB Microscope Slides.

Glass microscope slides were used for UV-visible, water contact angle (WCA), and static XPS analysis as support material for thin film preparation and negatively charged substrates were obtained by dipping these microscope slides into freshly prepared piranha solution for $1 \mathrm{~h}$. For dynamic XPS measurements, HF-cleaned Si (100) wafers with a thin oxide layer which was grown by thermal treatment at $700^{\circ} \mathrm{C}$ for $3 \mathrm{~h}$ in air were used as support material. These silicon substrates were 
negatively charged by dipping into $0.1 \mathrm{M} \mathrm{NaOH}$ solution also for $1 \mathrm{~h}$.

Adsorption of polyelectrolyte layers on negatively charged substrates (microscope glass slides or silicon wafers) were performed by dipping cycles of $40 \mathrm{~min}$ of negatively charged substrate into oppositely charged polyelectrolyte solutions starting from positively charged $0.5 \mathrm{~g} / \mathrm{l}$ PEI solution. For further construction of polyelectrolyte layers, adsorption process was performed by sequential dipping into $0.5 \mathrm{~g} / \mathrm{l}$ of PSS and PAH solution in the presence of $0.15 \mathrm{M}$ $\mathrm{NaCl}$ solution as established before. ${ }^{10-19}$ Negatively capped $\mathrm{AgCu}$ nanoparticles were prepared by the coreduction $1 \mathrm{ml}$ of $0.01 \mathrm{M}$ of silver and copper ions in the presence of very strong reducing agent, hydrazine hydrate, stabilizer cysteine, and the complexing agent sodium citrate as described in details in our previous work. ${ }^{9}$ These citrate capped negatively charged nanosized $\mathrm{AgCu}$ particles were incorporated on to the positively charged polyelectrolyte layer by dipping the substrate into the $\mathrm{AgCu}$ Nanoparticles solution for $18 \mathrm{~h}$. Samples were washed in between adsorption cycles in order to remove unbounded or weakly bounded materials and dried under flow of nitrogen gas for $1 \mathrm{~min}$.

WCA measurements were performed by Tantec contact angle meter to determine adsorption of the PSS and PAH layers because negatively or positively charged polyelectrolyte layers display different wetting characteristics. ${ }^{21}$ Double beam thermo scientific evolution $160 \mathrm{UV}$-visible spectrophotometer was used for optical characterization of nanoalloy containing thin films. A thermo scientific K-alpha spectrometer, with $\mathrm{Al} \mathrm{K} \alpha$ monochromatic $\mathrm{x}$-ray source, is used for XPS measurements. Samples were analyzed under $\mathrm{X}$-rays with $45^{\circ}$ angle and the kinetic energy analyzer with $90^{\circ}$ with respect to the surface of sample plane. The sample holder can be connected to either ground (for static measurements) or to a function generator (Stanford Research Systems DS340) providing the SQW pulses with desired frequency and amplitude (for dynamic measurements).

\section{RESULTS AND DISCUSSION}

High molecular weight, positively charged and branched PEI, which forms an irreversible bounded stable single thin layer on negatively charged glass substrate, was used as a base layer for further construction of polyelectrolyte layers. The WCA measurements were utilized as a practical and simple method for assessing surface modification before further spectroscopic analysis. Adsorption of negatively charged PSS layer on the PEI layers was confirmed by the WCA value around $40^{\circ}$ and further adsorption of positively charged PAH layer on PSS layer was confirmed by an increase in the contact angle value to around $70^{\circ}$, consistent with literature data. ${ }^{1,7}$ Properly charged $\mathrm{AgCu}$ nanoparticles were attached on to the thin films via alternating adsorption of oppositely charged nanoparticles and polyelectrolytes as a result of electrostatic attachment of negatively capped nanoparticles on positively charged polyelectrolyte layers. Adsorption of the $\mathrm{AgCu}$ nanoparticles on ultrathin PEI-PSS-PAH polyelectrolyte layers was asserted by optical characterization at the outset. UV-visible spectrum after the deposition of $\mathrm{AgCu}$ nanoparticles on top of the PEI-PSS-PAH thin layers is given in Fig. 1(b), with the characteristics absorbance at $420 \mathrm{~nm}$ corresponding to the existence of nanoparticles, which is only slightly shifted and broadened from the spectrum of Ag-only nanoparticles, shown in Fig. 1(a). As was discussed in our previous work, these particles and ultrathin films containing them exhibit very high antibacterial activity toward Escherichia coli, when compared to $\mathrm{Ag}$-only and $\mathrm{Cu}$-only nanoparticles. In the same figure, the XRD patterns of the Ag-only [Fig. 1(c)] and $\mathrm{AgCu}$ [Fig. 1(d)], nanoparticles are reproduced, as published in previous work, where no pattern is discernible for the latter. ${ }^{9}$ We now turn to dynamical XPS measurements for harvesting additional information about the structure of these ultrathin films.

Initially, conventional, static XPS measurements were performed for the samples deposited both on glass and silicon substrates to monitor preparation and incorporation of $\mathrm{AgCu}$ nanoparticles into PEI-PSS-PAH ultrathin films by following the characteristic binding energies and atomic spin orbit structures of $\mathrm{Ag} 3 \mathrm{~d}$ and $\mathrm{Cu} 2 \mathrm{p}$ for the nanoparticles, and $\mathrm{C} 1 \mathrm{~s}, \mathrm{~N} 1 \mathrm{~s}$, and S2p for the PEI-PSS-PAH layers. Figure 2 shows an XPS survey spectrum of a typical film. The Ag3d and $\mathrm{Cu} 2 \mathrm{p}$ peaks reveal the presence of the zero-valent $\mathrm{Ag}$ and $\mathrm{Cu}$ nanoparticles, and $\mathrm{N} 1 \mathrm{~s}, \mathrm{~S} 2 \mathrm{p}$, and $\mathrm{C} 1 \mathrm{~s}$ peaks confirm the successful adsorption of PEI, PSS, and PAH polyelectrolyte layers. $\mathrm{C} 1 \mathrm{~s}$ peak arises from the carbon atoms of the polymer chains of both negatively and positively charged polyelectrolytes, as well as the capping layer of the nanoparticles. N1s peak originates from the positively charged $-\mathrm{NH}^{+}$group of PEI and $-\mathrm{NH}_{3}{ }^{+}$group of $\mathrm{PAH}$, and $\mathrm{S} 2 \mathrm{p}$ peak originates from negatively charged $-\mathrm{SO}_{3}{ }^{-}$group of PSS. When S2p region of XPS survey was examined in detail, two different peaks were detected corresponding to two different sulfur species as depicted in the inset of the Fig. 2. S2p peak at the higher binding energy represents the negatively charged $-\mathrm{SO}_{3}{ }^{-}$group of PSS layer, whereas $\mathrm{S} 2 \mathrm{p}$ peak at lower binding energy corresponds to the sulfur in the structure of cysteine, the nanoparticles' stabilizer, and the

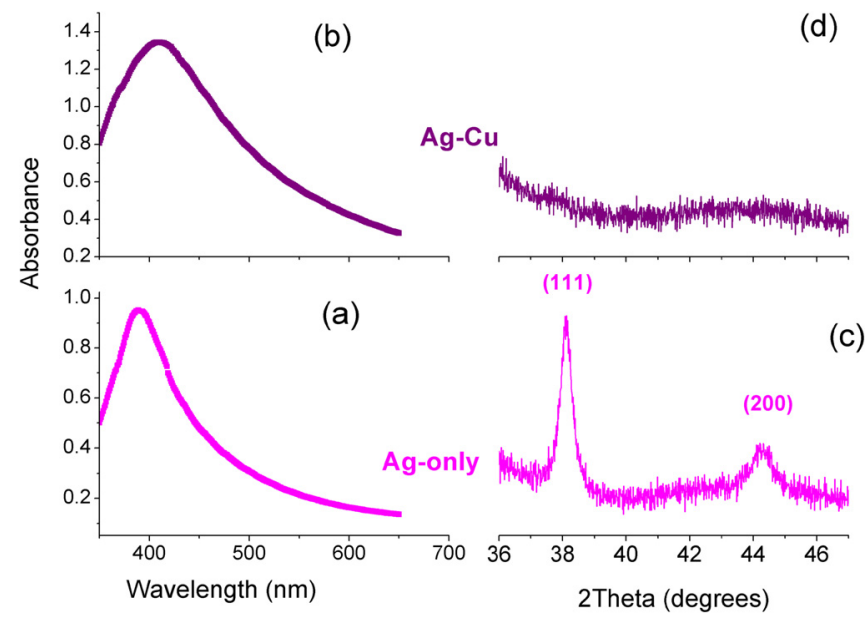

FIG. 1. (Color online) UV-visible absorption spectrum of the films containing; (a) Ag-only and (b) AgCu nanoparticles. XRD patterns of (c) Ag-only and (d) AgCu nanoparticles. 


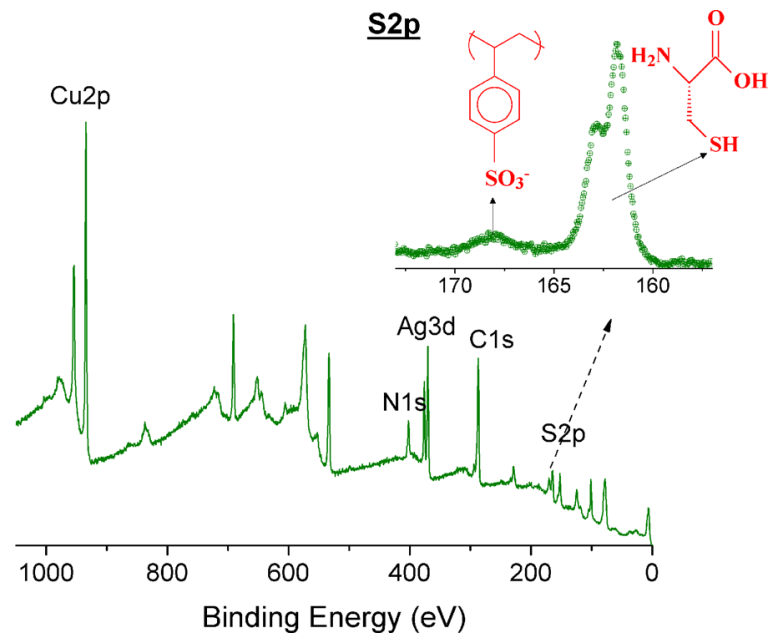

FIG. 2. (Color online) Conventional XPS survey spectrum of the PEI-PSS-PAH film containing Ag-Cu nanoalloys on Si substrate. The inset shows the $\mathrm{S} 2 \mathrm{p}$ region in detail.

capping agent. The difference in the intensities of these $S 2 p$ peaks arises from the orientation of the thin layers since the $\mathrm{Ag}$ and $\mathrm{Cu}$ nanoparticles were incorporated at the outermost layer on top of PEI-PSS-PAH layers so that the intensity of the S2p corresponding to sulfur atom of cysteine is higher than the intensity of the S2p peak of underneath PSS layer. Also visible are the Si2s and 2p peaks of the substrate.

In order to confirm that $\mathrm{Ag}$ and $\mathrm{Cu}$ nanosized particles exist within proximity of each other and/or within the same alloy structure, dynamic XPS measurements were performed on the same samples deposited on conducting silicon substrates. XPS spectra of $\mathrm{Ag} 3 \mathrm{~d}, \mathrm{Cu} 2 \mathrm{p}, \mathrm{C} 1 \mathrm{~s}, \mathrm{~N} 1 \mathrm{~s}$, and S2p regions were recorded, while applying square wave pulses with a known frequency and amplitude. Dynamical XPS measurements bring out similarities and differences in charging properties of surface structures for extracting additional information about the chemical/physical nature of the samples under investigation. In our earlier work, it was pointed out that application of an external negative voltage bias induces extra positive charging shifts in the XPS peaks of nonconducting samples or surface structures if the polarity of the bias is negative, whereas positive bias decreases the extent of the charging shifts. ${ }^{32-34}$

We have also shown that the effects of both positive and negative bias together can be realized with application of a SQW excitation, where dynamics of charging can be extracted from the frequency dependence of the peaks. ${ }^{35}$ These processes are depicted in Fig. 3 for a copper metal strip. When the sample is grounded (conventional XPS), the spin-orbit doublets of the Cu2p level are observed at 932.70 and $952.50 \mathrm{eV}$ [Fig. 3(a)]. When subjected to +7 and $-7 \mathrm{~V}$ dc bias, the peaks shift exactly +7.00 and $-7.00 \mathrm{eV}$, respectively, since the sample is a conductor [Figs. 3(b) and 3(c)]. Application of a SQW excitation with $7 \mathrm{~V}$ amplitude is equivalent to application of $+7 \mathrm{~V}$ and $-7 \mathrm{~V}$ simultaneously and twins the peaks, such that a difference of $14.00 \mathrm{eV}$ $(2 \times 7)$ is measured between them at all frequencies for the conducting/noncharging samples [Figs. 3(d) and 3(e)]. If the sample or any of the surface domains is nonconducting or

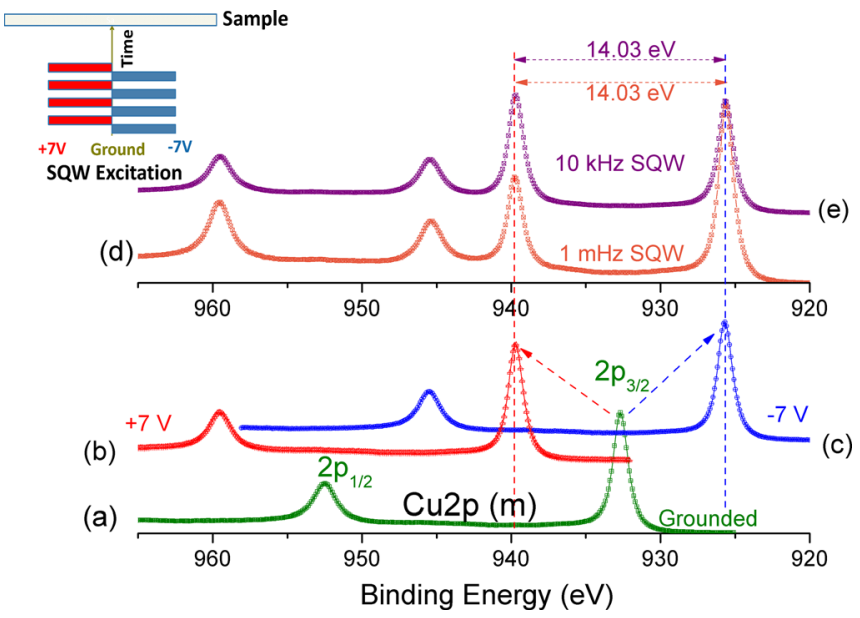

FIG. 3. (Color online) $\mathrm{Cu} 2 \mathrm{p}$ region of a $\mathrm{Cu}$ metallic sample recorded when: (a) grounded, (b) subjected to +7 , (c) and $-7 \mathrm{~V}$ d.c. voltage bias. The same region recorded when the sample is subjected to SQW excitation of $7 \mathrm{~V}$ amplitude and; (d) with $10 \mathrm{kHz}$, and (e) $0.001 \mathrm{~Hz}$ frequencies. The inset shows the Dynamic XPS schematically.

charging, a difference of less than $14.00 \mathrm{eV}$ will be recorded at low frequencies, since plenty of time is allowed for them to charge and discharge. At higher frequency, the $14.00 \mathrm{eV}$ difference will be resumed since the sample will not have time to charge or discharge. The measured value of 14.03 , instead of $14.00 \mathrm{eV}$, stems from the accuracy of the wave-generator used.

Hence, this procedure involving measurements at different frequencies brings out charging properties of surface moieties. ${ }^{35}$ In general, charging and discharging of nonconducting materials during XPS measurements are complex phenomena involving a number of cascading physical and chemical processes, and such measurements involving several frequencies bring out information, related to these processes, but this is a very tedious and time consuming process. ${ }^{36} \mathrm{We}$, however, will not dwell on them but concentrate only on the correlation of the shifts in peak positions. Therefore, if one is looking for simple correlations between the peaks, two measurements at a reasonably high and low frequencies will be sufficient, since they will correspond to the two extremes; highly charged and uncharged states, respectively. Accordingly, only the measurements at $7 \mathrm{~V}$ amplitude and $0.001 \mathrm{~Hz}$ and $10 \mathrm{kHz}$ are presented for spectral clarity.

According to their dynamic XPS behavior of the spectral features of our films, we can assign the XPS peaks into two groups. The first group comprises of the Cu2p, Ag3d, and the S2p of cysteine, which are shown in Fig. 4(a). All these spectral features display $14.03 \mathrm{eV}$ shifts at the $10 \mathrm{kHz}$ excitation and $13.81 \mathrm{eV}$ at the lower $0.001 \mathrm{~Hz}$ excitation. As shown in Fig. 4(b), the behavior of the peaks in the second group is also similar to the first one at the higher frequency of $10 \mathrm{kHz}$, namely, $13.98 \mathrm{eV}$. However, at the lower frequency, they display significantly differing shifts from the first group as well as among them. The $\mathrm{C} 1 \mathrm{~s}$ and the N1s peaks display the same shift of $13.59 \mathrm{eV}$, and the $\mathrm{S} 2 \mathrm{p}$ of the $-\mathrm{SO}_{3}{ }^{-}$moieties displays the most deviated shift of $13.50 \mathrm{eV}$ at $0.001 \mathrm{~Hz}$.

Note that in general, species display different charging shifts, as observed for the peaks of the polyelectrolytes, hence observation of any correlation between peaks 

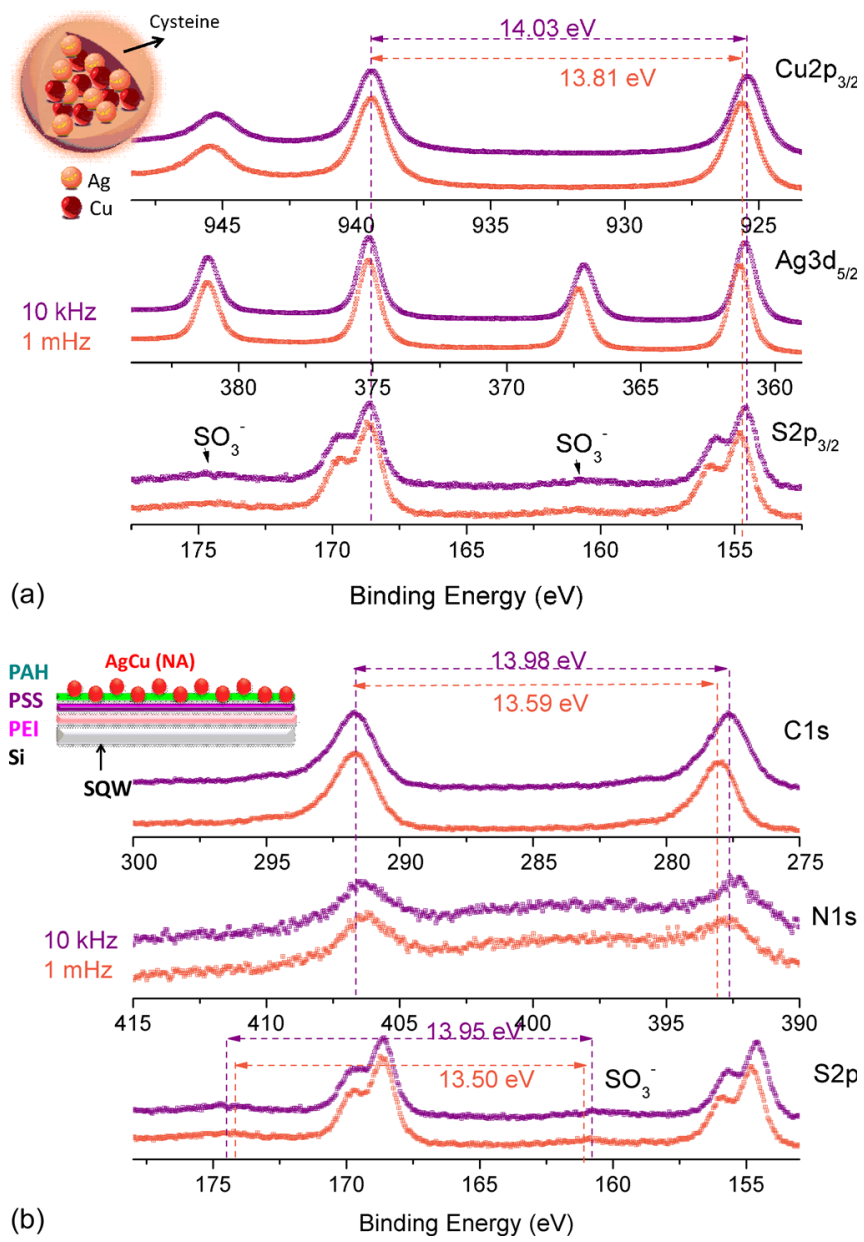

FIG. 4. (a) (Color online) Dynamic XPS spectra showing the Cu2p, Ag3d, and S2p regions of the same film recorded under SQW excitation at $10^{4}$ and $10^{-3} \mathrm{~Hz}$ frequencies. The inset shows schematically the nano-alloy structure. (b) C1s, N1s, and S2p regions recoerded under SQW excitation at $10^{4}$ and $10^{-3} \mathrm{~Hz}$ frequencies. The inset shows the application of the SQW excitation and the composition of the film schematically.

representing different species is a strong indication of the presence of an electronic interaction. Accordingly, a simple interpretation of these findings is that $\mathrm{Ag}$ and $\mathrm{Cu}$ atoms are together inside their capping agent, cysteine, and have very similar charging properties, differing significantly from the polyelectrolytes. This also implies that the metal atoms are in electrical contact, i.e., within the proximity of each other as in an alloy structure, consistent also with the observed UV-Vis spectrum. Considering also the fact that no XRD pattern was observed, these highly effective antibacterial $\mathrm{AgCu}$ nanoalloys must have some disordered random distribution of $\mathrm{Ag}$ and $\mathrm{Cu}$ atoms within the enclosed structure.

\section{SUMMARY AND CONCLUSIONS}

In summary, we have applied SQW excitation to the sample for performing dynamical XPS measurements on ultrathin polyelectrolyte layers containing $\mathrm{Ag}$ and $\mathrm{Cu}$ metal nanoparticles. Through such measurements, we were able observe strong correlation of the charging behavior of these two metal atoms, as well as the $\mathrm{S}$ atom of their capping agent, revealing that they are within close proximity of each other as in a nanoalloy structure. The procedure is simple to implement and has the potential of harvesting electrical and dielectric properties of surface structures, in addition to the rich chemical information obtainable by XPS. We will extend such similarity analysis to other frequencies and possibly obtain more information about the relative charge-built up in a chemically specific fashion in the nanoalloys with respect to the polyelectrolyte layers and/or the silicon oxide substrate.

\section{ACKNOWLEDGMENTS}

The authors thank Isik G. Yulug and Nilufer Sayar of the Department of Molecular Biology and Genetics of Bilkent University. They also acknowledge the financial support of TUBITAK through the Grant 211T029.

${ }^{1}$ C. J. Murphy, T. K. Sau, A. M. Gole, C. J. Orendorff, J. Gao, L. Gou, S. E. Hunyadi, and T. Li, J. Phys. Chem. B 109, 13857 (2005).

${ }^{2}$ W. P. McConnell, J. P. Novak, L. C. Brousseau III, R. R. Fuierer, R. C. Tenent, and D. L. Feldheim, J. Phys. Chem. B 104, 8925 (2000).

${ }^{3}$ D. I. Gittins, D. Bethell, D. J. Schiffrin, and R. J. Nichols, Nature 408, 67 (2000).

${ }^{4}$ C. Burda, X. Chen, R. Narayanan, and M. A. El-Sayed, Chem. Rev. 105, 1025 (2005).

${ }^{5}$ R. Narayanan and M. A. El-Sayed, J. Phys. Chem. B 109, 12663 (2005).

${ }^{6}$ M. Kralik and A. Biffis, J. Mol. Catal. A: Chem. 177, 113 (2001).

${ }^{7}$ X. Luo, A. Morrin, A. J. Killard, and M. R. Smyth, Electroanalysis 18, 319 (2006).

${ }^{8}$ H. Pang, F. Gao, and Q. Lu, Chem. Commun. 1076 (2009).

${ }^{9}$ M. Taner, N. Sayar, I. G. Yulug, and S. Suzer, J. Mater. Chem. 21, 13150 (2011).

${ }^{10}$ J. Sanchez, J. Stark, and V. Moruzzi, Phys. Rev. B 44, 5411 (1991).

${ }^{11}$ J. Yun, K. Cho, H. C. Kang, B. K. Ju, and S. Kim, Jpn J. Appl. Phys., Part 147,5070 (2008).

${ }^{12}$ G. Decher, Science 277, 1232 (1997).

${ }^{13}$ Y. Shimazaki, M. Mitsuishi, S. Ito, and M. Yamamoto, Langmuir 13, 1385 (1997).

${ }^{14}$ G. Decher, M. Eckle, J. Schmitt, and B. Struth, Curr. Opin. Colloid Interface Sci. 3, 32 (1998).

${ }^{15}$ G. B. Sukhorukov, E. Donath, H. Lichtenfeld, E. Knippel, M. Knippel, A. Budde, and H. Möhwald, Colloids Surf., A 137, 253 (1998).

${ }^{16}$ N. A. Kotov, Nanostruct. Mater. 12, 789 (1999).

${ }^{17}$ P. Podsiadlo, S. Paternel, J. M. Rouillard, Z. Zhang, J. Lee, J. W. Lee, E. Gulari, and N. A. Kotov, Langmuir 21, 11915 (2005).

${ }^{18}$ P. Podsiadlo et al., Langmuir 23, 7901 (2007).

${ }^{19}$ E. Kharlampieva and S. A. Sukhishvili, Langmuir 20, 9677 (2004).

${ }^{20}$ P. Kamat, J. Phys. Chem. B 106, 7729 (2002).

${ }^{21}$ M. Elzbieciak, M. Kolasinska, and P. Warszynski, Colloids Surf. A 321, 258 (2008).

${ }^{22}$ D. L. Feldheim and C. A. Foss, Metal Nanoparticles: Synthesis, Characterization, and Applications (Marcel Dekker Inc., New York, 2002).

${ }^{23}$ H. Wang, Y. Huang, Z. Tan and X. Hu, Anal. Chim. Acta 526, 13 (2004).

${ }^{24}$ W. C. Bell and M. L. Myrick, J. Colloid Interface Sci. 242, 300 (2001).

${ }^{25}$ Y. H. Kim, D. K. Lee, H. G. Cha, C. W. Kim, and Y. S. Kang, J Phys. Chem. C 111, 3629 (2007).

${ }^{26}$ W. Songping and M. Shuyuan, Mater. Lett. 60, 2438 (2006).

${ }^{27}$ S. Shibli, B. Jabeera, and R. Manu, Mater. Lett. 61, 3000 (2007).

${ }^{28}$ M. S. Bootharaju and T. Pradeep, J. Phys. Chem. C 114, 8328 (2010).

${ }^{29}$ R. T. Tom, A. K. Samal, T. S. Sreeprasad, and T. Pradeep, Langmuir 23, 1320 (2007).

${ }^{30}$ K. Siegbahn, Science 217, 111 (1982).

${ }^{31}$ D. Briggs and M. P. Seah, Practical Surface Analysis (Wiley, Chichester 1983), p. 1.

${ }^{32}$ G. Ertas and S. Suzer, Surf. Interface Anal. 36, 619 (2004).

${ }^{33}$ C. P. Conger and S. Suzer, Langmuir 25, 1757 (2009).

${ }^{34}$ S. Suzer, H. Sezen, G. Ertas, and A. Dana, J. Electron Spectrosc. Relat. Phenom. 176, 52 (2010).

${ }^{35}$ H. Sezen and S. Suzer, Surf. Sci. 604, L59 (2010).

${ }^{36}$ J. Cazaux, J. Electron Spectrosc. Relat. Phenom. 105, 155 (1999). 